\title{
EVOLUÇÃO DA ARQUITETURA INSTITUCIONAL DE CONTROLE E DEFESA DO ESTADO BRASILEIRO
}

\author{
EVOLUTION OF THE INSTITUTIONAL ARCHITECTURE OF CONTROL \\ AND DEFENSE OF THE BRAZILIAN STATE
}

\begin{abstract}
RESUMO
O presente trabalho versa sobre a evolução da arquitetura institucional do controle interno brasileiro numa perspectiva de identificar as transformações decorridas na estrutura de defesa administrativa do Estado. Sob a perspectiva neo-institucionalista da trajetória desde sua criação na prevenção e combate à corrupção, analisa-se a Controladoria-Geral da União, desde a sua formação até a mudança com a criação do Ministério da Transparência e Controladoria-Geral da União, em 2017. Enquanto órgão central do Sistema de Controle Interno do Poder Executivo Federal, o presente trabalho analisa as constantes transformações no curso das demandas institucionais sofridas pelo órgão. Dessa forma, é possível adiantar que a compreensão da formação histórica e consequente desempenho da CGU é aspecto importante no desenvolvimento de uma gestão pública pautada na integridade, uma vez que a concepção do controle administrativo governamental é fruto das iniciativas de modernização do aparato público. Capaz de induzir uma gestão pública mais eficiente e racional, a atuação da CGU indica o fortalecimento da transparência pública, da probidade administrativa e lisura dos servidores federais, possibilitada pela sua centralização administrativa, instituição de quadro próprio e formalização de competências legais, determinantes para a própria administração pública melhorar os serviços oferecidos aos cidadãos. A ideia de uma agência central independente de controle e correição indica a consolidação da política de combate à corrupção. Tendo em vista a necessidade de respostas à altura, a evolução do controle interno governamental superou o simples controle de contas para abarcar iniciativas de monitoramento e responsabilização.
\end{abstract}

Palavras-chave: Controle Interno; Desenvolvimento institucional; CGU.

\section{ABSTRACT}

This paper deals with the evolution of the institutional architecture of Brazilian internal control in order to identify the transformations that have taken place in the state's administrative defense structure. From the neo-institutionalist perspective of the trajectory since its creation in the prevention and combat of corruption, the Comptroller General of the Union is analyzed, from its formation until the change with the creation of the Ministry of Transparency and Comptroller General of the Union, in 2017. 
As the central agency of the Federal Executive Branch's Internal Control System, this paper analyzes the constant changes in the course of the institutional demands suffered by the agency. Thus, it is possible to advance that the understanding of the historical formation and consequent performance of the CGU is an important aspect in the development of a public management based on integrity, since the conception of governmental administrative control is the result of initiatives of modernization of the public apparatus. Able to induce a more efficient and rational public management, CGU's actions indicate the strengthening of public transparency, administrative probity and fairness of federal employees, made possible by its administrative centralization, the establishment of its own framework and the formalization of legal competences, which are crucial for public administration itself improve the services offered to citizens. The idea of an independent central agency for control and correction indicates the consolidation of anti-corruption policy. Given the need for timely responses, the evolution of government internal control has surpassed simple account control to encompass monitoring and accountability initiatives.

Keyword: Internal Control; Institutional development; CGU.

\section{INTRODUÇÃO}

O presente trabalho aborda a evolução organizacional do principal órgão incumbido de conduzir as atividades de controle interno e defesa administrativa do Estado brasileiro no governo federal. Sob a perspectiva da trajetória institucional e sua atuação sistemática na prevenção da corrupção, analisa-se a trajetória institucional como aspecto favorável ao fortalecimento da integridade administrativa pública federal. Encabeçada pela Controladoria-Geral da União (CGU), é este o órgão central do Sistema de Controle Interno do Poder Executivo Federal, responsável por avaliar o cumprimento das metas estabelecidas pelo Plano Plurianual, fiscalizar o orçamento da União e o desenvolvimento dos programas de governo, além da gestão dos servidores públicos federais.

A compreensão da formação histórica e consequente desempenho da CGU é aspecto importante no desenvolvimento da gestão pública, uma vez que a concepção do controle administrativo governamental é fruto das iniciativas de modernização do aparato público e da mudança de cultura administrativa (OLIVIERI, 2011). Capaz de induzir uma gestão pública mais eficiente e racional por meio de instrumentos como a auditoria e das fiscalizações financeiras, contábeis, orçamentárias, patrimoniais e operacionais, a atuação da CGU representa o fortalecimento da transparência pública, da probidade administrativa e lisura dos servidores federais.

A partir da década de 1980 emerge uma diferenciação entre os conceitos de modernização e reformas (RAMIÓ, 1996, apud VARELA ÁLVAREZ, 2010, p. 160), quando se tornaram corriqueiras as ações denominadas "programas de modernizações" nas administrações ocidentais, rompendo com a ideia de 
"reforma" - até então permeada de fracassos nas décadas de 1960 e 1970 (ECHEVARRÍA LOSADA, 1993, apud VARELA ÁLVAREZ, 2010, p. 160). Não obstante, Varela Álvarez (2010) afirma que todas essas iniciativas, independentes dos diferentes contextos, acabaram por abarcar os princípios de orientação à melhora dos serviços e atualização do aparato burocrático na contemporaneidade.

Com o surgimento de novas instituições políticas, entre elas os tribunais de contas, observou-se um importante redesenho do aparato estatal brasileiro na busca pelo controle das finanças públicas. Outro ponto relevante foi o impacto da redemocratização, materializada na Constituição de 1988, trazendo competências e preocupações antes não consideradas pelo Estado.

Inseridos no sistema de accountability, os tribunais de contas surgiram no advento da República como órgãos responsáveis pela fiscalização da administração pública financeira. A função de controle dos gastos foi além, na medida em que estes órgãos assumiram também a responsabilidade de controlar o desempenho e desenvolvimento das políticas, promovendo a correção de problemas identificados no uso dos recursos.

Nesse sentido, a accountability horizontal (O'DONNELL, 1998) se apresenta como mecanismo de prestação de contas, pressupondo o constante acompanhamento administrativo, capaz de impor sansões aos gestores e consequente responsabilização. Ou seja, a "accountability política é, portanto, uma relação entre um ator ou órgão de controle e um agente público (seja político ou burocrata). Essa relação se caracteriza pela obrigação legal do agente público de responder ao ator ou órgão de controle" (OLIVIERI, 2011, p. 1398).

Para Olivieri (2011), esse desenvolvimento burocrático no contexto de prestação de contas favorece a fiscalização entre o agente público e o órgão controlador. Objetivando a correta utilização do erário, a probidade administrativa entrou na agenda dos órgãos de controle interno como um avanço no fortalecimento da relação de democratização do setor público, uma vez que favorecem a transparência e responsabilização da ação governamental (OLIVIERI, 2011)

É nesse contexto que a Constituição de 1988 criou um solo fértil para o nascimento de diversas novidades no campo da democratização dos serviços públicos. Exemplos como as ouvidorias, transparência pública, e a edição da lei de acesso à informação vêm contribuindo para o fortalecimento das atividades de controle em todo o país. Proporcionado pela iniciativa de modernização da administração pública para melhorar a eficiência, relevantes medidas foram

Lei $\mathrm{N}^{\circ} 12.527$, de 18 de novembro de 2011. Regula o acesso a informações previsto no inciso XXXIII do art. $5^{\circ}$, no inciso II do $\$ 3^{\circ}$ do art. 37 e no $\$ 2^{\circ}$ do art. 216 da Constituição Federal; altera a Lei $n^{\circ} 8.112$, de 11 de dezembro de 1990; revoga a Lei ${ }^{\circ} 11.111$, de 5 de maio de 2005, e dispositivos da Lei $n^{\circ} 8.159$, de 8 de janeiro de 1991; e dá outras providências. 
empreendidas nesse sentido, principalmente no que diz respeito ao monitoramento das políticas públicas (OLIVIERI, 2011).

Esse monitoramento em relação à execução das políticas públicas é, entre outras, uma atribuição da Presidência da República, o qual é compartilhado com o Congresso Nacional no que diz respeito à fiscalização do Executivo por meio do controle externo, ou seja, aquele desempenhado pelo Tribunal de Contas da União (OLIVIERI, 2011). Cabe ao executivo, portanto, o controle político sobre a burocracia no esforço de monitorar o desempenho da atuação e a legalidade dos atos decorrentes.

Para se ter uma dimensão dos resultados que envolvem as atividades de controle interno, segundo dados do órgão², entre 2003 e 2015 foram conduzidas 199 operações especiais em conjunto com os demais órgãos de defesa do Estado. No mesmo período sofreram punições, como demissão, cassação de aposentadorias ou destituição do cargo, o número de 5.659 servidores públicos federais. Desse total de punições expulsivas, cerca de $66 \%$ são fundamentadas por atos relacionados à corrupção.

A capacidade da CGU deflagrar e conduzir operações de combate à corrupção é a expressão máxima da atuação no controle interno e fiscalização determinados pela Constituição Federal. De acordo com dados disponibilizados pelo Relatório de Atividades do órgão, em 2015 foram conduzidas 32 ações investigativas, em 16 unidades da federação, o que representou a identificação de prejuízos na ordem de $\mathrm{R} \$ 454$ milhões, ou ainda 102 mandados de prisão temporária ou preventiva com participação da CGU.

Nesse contexto, enquanto instituição munida de normas e regras, valores e processos, traz-se o enfoque neo-institucionalista a fim de considerar a relação do entorno organizacional no desenvolvimento institucional. Nesse âmbito, Salvador Serna (2001) entende que no neo-institucionalismo as tomadas de decisões são orientadas pelas estruturas, uma vez que estão envolvidas pelos valores e regras que acompanham as "decisões num contexto da racionalidade limitada" (MARCH \& SIMON, 1987, apud SALVADOR SERNA, 2001, p. 03).

Portanto, procura-se avaliar institucionalmente as possíveis influências que a própria organização induz para corroborar com as mudanças e assim melhorar o entendimento da atual conjuntura estrutural do órgão de controle. Uma vez que a disposição administrativa interfere nas tomadas de decisões dos agentes (SALVADOR SERNA, 2001), o enfoque neo-institucionalista é relevante

\footnotetext{
Relatório de acompanhamento das punições expulsivas aplicadas a estatutários no âmbito da administração pública federal (Dez/2016) da Corregedoria-Geral da União, Ministério da Transparência, Fiscalização e Controle.
} 
na análise da trajetória percorrida pelo controle interno, de forma a justificar os diferentes níveis de legitimidade dos governos ao controle político-administrativo brasileiro.

\section{SURGIMENTO DO CONTROLE NO BRASIL}

Atrelado ao controle das contas públicas (ARAÚJO, 1993, apud BRITO, 2009, p 03), o controle interno no Brasil pode ser associado ao princípio da colonização empreendida por Portugal em meados de 1530, uma vez que eram recolhidos impostos e havia a fiscalização sobre todos os bens explorados na colônia - inicialmente a madeira, passando pelo açúcar, até chegar ao período áureo da mineração (NAKANO, 2017). Já no século XVIII, com a diminuição da arrecadação do ouro e visando identificar supostos desvios e contrabandos do metal, foi decretado o código pombalino ${ }^{3}$ em 1761, o qual criou a primeira instituição centralizada de fiscalização por parte do Estado português. Denominado "Erário Régio", tinha como finalidade o acompanhamento da rentabilidade das colônias e suas contabilidades financeiras, passando a abarcar não somente os faturamentos, mas todas as gestões fazendárias.

Com a vinda da família real portuguesa para o Brasil em 1808, fugindo das incursões de Napoleão Bonaparte que havia decretado o bloqueio continental, transferiu-se também todo o aparato administrativo da Coroa, implantando, além do já existente Erário Régio, o conselho da fazenda, responsável por dirigir os fundos públicos. Destaca-se que a maior centralização e fortalecimento das instituições de controle econômico-financeiro refletiu num importante passo no combate aos desvios e consequentes corrupções.

Não obstante, para Jaime Brito (2009), o marco que melhor define o início do controle da gestão governamental no Brasil é o ano de 1822, após a independência, ao se fundar o Tesouro Nacional. Isso porque em 1831 foi instituído o Tribunal do Tesouro Público Nacional, abarcando também as atividades do Conselho da Fazenda, permitindo que se fizesse a "administração da despesa e das receitas públicas, da contabilidade e dos bens nacionais, o recebimento das prestações de contas anuais de todas as repartições e a análise dos empréstimos e da legislação fazendária" (BRITO, 2009, p. 03). Mais tarde, surgido em 1890, o Tribunal de Contas da União foi instituído como uma instância julgadora das operações financeiras brasileiras, atuando como uma corte de fiscalização.

O modelo de gestão racional-legal, de valorização da burocracia enquanto instrumento essencial da Administração, só foi introduzido após 1936,

Conjunto de medidas adotadas pelo Marquês de Pombal a fim de reequilibrar as contas nacionais de Portugal. 
com a criação do Departamento Administrativo do Serviço Público (DASP). O DASP, órgão federal criado pelo presidente Getúlio Vargas para assessorar a Presidência da República na elaboração da proposta orçamentária, foi um importante avanço, pois auxiliou na modernização e melhoria do Estado brasileiro. O DASP, então, introduziu na administração pública brasileira os princípios da formalidade, impessoalidade e profissionalismo, ou seja, os elementos da burocracia weberiana.

Em 17 de março de 1964, com a entrada em vigor da Lei $n^{\circ}$ 4.320, que instituiu as normas gerais do direito financeiro para o controle dos orçamentos nos três níveis da federação, regulamentou-se também o controle interno como responsável pela verificação prévia da legalidade e tomadas de contas. De acordo com Brito (2009), o controle a priori representou uma mudança expressiva no sistema tradicional, ao munir a capacidade do Estado de se antecipar aos problemas relativos ao orçamento. Para Olivieri (2010), essa foi uma das maiores reformas do controle interno, pois implantou a utilização do termo "controle concomitante" em substituição ao controle exclusivamente contábil e financeiro, conforme consta no artigo 77 do Capítulo II do Controle Interno, da referida legislação.

Após a implantação do regime militar brasileiro em 1964, e em meio a uma reforma administrativa conduzida pelo presidente Humberto Castello Branco, foi sancionado o Decreto-Lei ${ }^{\circ} 200$, em 25 de fevereiro de 1967. Este decreto, além de reorganizar toda a administração federal e estabelecer suas diretrizes, determinou que o controle e fiscalização dos programas fossem conduzidos pelos órgãos e agentes responsáveis pela sua implementação. Com isso, criaram-se as inspetorias gerais de finanças, alocadas cada uma em seus respectivos ministérios civis. Tal iniciativa, fortemente amparada na ideia do estado gerencial (OLIVIERI, 2010), significou a "adoção de novas tecnologias de gestão do gerencialismo, como, por exemplo, a descentralização, a delegação de responsabilidades para os gestores e (...) a substituição dos controles formais pelo controle de resultados" (OLIVIERI, 2010, p. 84).

Em 31 de dezembro de 1979, com a publicação do Decreto $n^{\circ} 84.362$, as inspetorias gerais de finanças foram extintas, transformando-se em secretarias de controle interno, mais conhecidas como CISET. Essa alteração incluiu em suas obrigações a competência de supervisionar física e financeiramente as atividades e projetos desenvolvidos pelo seu ministério ou órgão correspondente. Na mesma toada, foi instituída também pelo decreto a Secretaria Central de Controle Interno (SECIN), subordinada diretamente à Secretaria de Planejamento da Presidência da República, responsável pela supervisão técnica das 
CISETs e auditorias contábeis em toda a administração federal - sem o prejuízo das próprias supervisões ministeriais.

A estrutura da Secretaria Central de Controle Interno perdurou até 1986, quando foi instituído o decreto $\mathrm{n}^{\circ} 92.452$, em 10 de março, extinguindo-a em substituição à Secretaria do Tesouro Nacional (STN), agora dentro do Ministério da Fazenda. A STN foi concebida para compor a coordenação e o controle financeiro federal, sendo um dos órgãos centrais do controle interno e planejamento da União. Entretanto, as atividades de auditorias contábeis e de programas ministeriais continuaram delegadas às respectivas CISET.

A configuração do controle interno encabeçada pela STN manteve-se até a reforma administrativa da década de 1990, com a sanção da medida provisória $\mathrm{n}^{\circ} 480$, em 27 de abril de 1994. Essa medida reorganizou o sistema de controle interno, criando a Secretaria Federal do Controle Interno (SFC), compondo-a em conjunto com a STN e as CISETs como os principais órgãos e unidades do sistema. Com isso, a MPV 480/1994 ainda formalizou as saídas das CISETs dos seus ministérios, subordinando-as à SFC - fato este considerado relevante, pois significou uma ruptura na hierarquia, retirando do comando dos ministros a chefia dos órgãos responsáveis pelo controle de suas próprias gestões (OLIVIERI, 2010).

De acordo com Olivieri (2010), essa reforma empreendida em princípios da década de 1990, foi capaz de reestruturar o sistema de controle interno ao criar a SFC como um autêntico órgão de centralização das atividades do sistema, acompanhado da STN. Em suma, observa-se ao longo de 1967 até 1994 a vigência de um sistema de controle descentralizado, controle esse exercido, basicamente, pela atuação setorial das CISETs. Então subordinadas aos ministérios, competiam a elas o controle do seu respectivo setor ou área governamental, cabendo à STN o acompanhamento e supervisão técnica.

Feita a revisão histórica do controle interno no Brasil, do princípio até as modificações observadas nos anos 1990, apresenta-se a seguir a compreensão institucional do controle interno federal a partir dos anos 2000. Pautado nos aspectos formais e legais, apresenta-se uma análise do desenvolvimento do controle interno até os dias atuais.

\section{CENTRALIZAÇÃO DO CONTROLE INTERNO PÓS ANOS 2000}

Nascido sob o nome de Corregedoria-Geral da União, criada por meio da medida provisória $\mathrm{n}^{\circ}$ 2.143-31, de 02 de abril de 2001, no governo do presidente Fernando Henrique Cardoso, esse novo órgão com posição de ministério tinha 
como objetivo combater a corrupção no Poder Executivo Federal, promovendo assim a defesa do patrimônio público.

Anunciada após os sucessivos escândalos de corrupção que envolveram autarquias federais de fomento e apoio ao desenvolvimento da região norte Superintendência de Desenvolvimento da Amazônia (SUDAM), e do nordeste - Superintendência de Desenvolvimento do Nordeste (SUDENE) - no início dos anos 2000, com as denúncias de desvio de recursos públicos das obras por elas financiadas, a medida provisória ${ }^{\circ}$ 2.143-31/2001 estabeleceu a criação e normativas de atuação da Corregedoria-Geral da União, dispondo esse órgão a função de, dentre outras, dar andamento às representações ou denúncias fundamentadas, instauração de sindicância, e acionamento da Advocacia-Geral da União aos casos de improbidade administrativa.

No ano seguinte, em 28 de março de 2002, foi instituído o decreto $\mathrm{n}^{\circ} 4.177$ que transferiu a Secretaria Federal de Controle Interno (SFC), conjuntamente com a Comissão de Coordenação de Controle Interno (CCCI), então pertencentes à Casa Civil da Presidência da República, para a Corregedoria-Geral da União. E pelo mesmo decreto a Ouvidoria-Geral, alocada junto ao Ministério da Justiça, também foi deslocada para sua estrutura, indicando o fortalecimento da instituição enquanto órgão central do sistema de controle interno federal.

Outro movimento administrativo de importante desdobramento, porém, foi dado pelo decreto $\mathrm{n}^{\circ} 4.308$, de 19 de julho de 2002 , o qual é o primeiro remanejamento de pessoal dos cargos do grupo de Direção e Assessoramento Superiores (DAS), então pertencentes ao Ministério da Fazenda, para a Corregedoria-Geral da União. Foram remanejados 301 cargos DAS e 33 funções gratificadas, o que culminou na primeira estrutura regimental de quadro dos cargos na CGU, e que passaram a se somar às estruturas anteriormente deslocadas pelo decreto $n^{\circ} 4 \cdot 177 / 2002$. Nessa toada, o primeiro decreto a aprovar a sua estrutura regimental foi o de $\mathrm{n}^{\circ} 4.490$, em 28 de novembro de 2002 , dispondo sobre sua natureza, competências, estrutura organizacional e unidades. É quando se tem a formalização de um aparato próprio e centralizado especificamente destinado à integridade governamental.

Em 2003, no governo do presidente Luiz Inácio Lula da Silva, com a medida provisória $n^{\circ}$ 103/2003, renomeou-se a Corregedoria-Geral da União para Controladoria-Geral da União. Uma das principais novidades dessa mudança, para além da nomenclatura, foi a inclusão da temática da transparência pública na agenda, ampliando, formalmente, as competências de corregedoria e controladoria federal no Brasil. 
Mantendo a sua subordinação à Presidência da República, a Controladoria-Geral da União (CGU) permaneceu com classe de ministério e como órgão auxiliar da chefia do Executivo Federal nos assuntos relativos à defesa do patrimônio público no âmbito de seu poder. Regulamentada pela lei $n^{\circ} 10.683 / 2003$, a CGU tinha como competências o fortalecimento da transparência pública e o combate à corrupção, desempenhando assim as atividades relativas ao controle interno.

Por meio desse desenvolvimento institucional a Controladoria-Geral da União reforçou sua estrutura como órgão central do Sistema de Controle Interno e do Sistema de Correição do Poder Executivo Federal. Como discorrido, a incorporação de estruturas anteriormente pertencentes a outros ministérios (Decreto $\mathrm{n}^{\circ} 4.177 / 2002$ ) foi uma iniciativa importante no enfrentamento da corrupção e da fraude no setor público. A defesa do patrimônio por meio da Secretara Federal de Controle Interno e da Ouvidoria-Geral, antes pertencentes ao Ministério da Fazenda e ao Ministério da Justiça, respectivamente, consolidou a centralização das atividades de controle interno propriamente ditas, e de ouvidoria pública.

Em 24 de janeiro de 2006, a composição da CGU foi reorganizada pelo Decreto $\mathrm{n}^{\circ} 5.683$, que aprovou uma nova estrutura regimental e seus respectivos cargos, melhorando sua eficácia e organicidade institucional com a criação inédita da Secretaria de Prevenção da Corrupção e Informação Estratégica (SPCI). A nova estrutura, ao incluir formalmente um departamento notadamente voltado à prevenção da corrupção, passou a dispor de área especialmente dedicada à atuação nos desvios de recursos e condutas dentro da administração federal, conferindo ao órgão a capacidade de se antecipar aos delitos e detecção de irregularidades, até então realizadas como atividades acessórias. São competências da SPCI, entre outros, o incremento da transparência pública, coleta e tratamento das informações estratégicas, acompanhamento da evolução patrimonial dos agentes públicos do Poder Executivo Federal, prevenção de conflitos de interesses nas funções, fomento à participação da sociedade civil na prevenção da corrupção, além de coordenar ações integradas de inteligência da CGU.

Outra relevante modificação na CGU foi feita em 17 de setembro de 2013, pelo Decreto $\mathrm{n}^{\circ} 8.109$, o qual atualizou a estrutura regimental e remanejou cargos em comissão. Essa normativa alterou a nomenclatura da então Secretaria de Prevenção da Corrupção e Informação Estratégica (SPCI) para Secretaria de Transparência e Prevenção da Corrupção (STPC), adequando-a para atuar em 
consonância à Lei de Acesso à Informação ${ }^{4}$, a Lei de Conflito de Interesses ${ }^{5}$, e a Lei Anticorrupção $0^{6}$ essas duas últimas, mais recentes, promulgadas após as manifestações populares de junho de 2013.

Nesse momento, então dotada de uma estrutura interna organizada em quatro áreas de atuações, a CGU vinha utilizando ferramentas consonantes com as modernizações implementadas pelas mais recentes legislações relacionadas ao combate à corrupção e responsabilização de crimes contra o patrimônio público. Como mencionado, o órgão foi atualizado pelo Decreto $n^{\circ}$ 8.109/2013, adotando novas configurações e nomenclaturas para os seus quatro departamentos finalísticos: a Secretaria Federal do Controle Interno (SFC), a Secretaria de Transparência e Prevenção da Corrupção (STPC), a Ouvidoria-Geral da União (OGU) e a Corregedoria-Geral da União (CRG).

São estas quatro áreas finalísticas que respondem pela implementação das atividades de controle interno propriamente ditas. Constituído de quatro setores articulados, cada um responde às intervenções de sua esfera e competência. Nos níveis subnacionais estão as controladorias regionais da CGU, alocadas em todas as capitais de estados, funcionando como escritórios descentralizados do órgão para auxiliar no desenvolvimento de atividades e aumentar a proximidade com os destinos dos recursos públicos a serem controlados.

Cabe à Secretaria de Transparência e Prevenção da Corrupção (STPC), a responsabilidade por formular, coordenar e fomentar todas as atividades relacionadas à prevenção da corrupção e o incremento da transparência pública. É dela também a competência de implementar o acesso à informação, contribuindo assim para o desenvolvimento da integridade no setor público, comprometido com a ética e a aproximação com a sociedade por meio do controle social dos gastos públicos.

À SFC cabe fiscalizar e avaliar o andamento dos programas governamentais financiados com recursos do orçamento federal, além de executar as auditorias, avaliar a gestão dos servidores da União e apurar denúncias. Para a STPC são atribuídas as ações de transparência, integridade, convênios e cooperações federativas. Já à OGU cabe a centralização de todas as demandas oriundas da sociedade, enquanto canal de interlocução da administração federal, servindo de entrada e instância recursal no âmbito da Lei de Acesso à Informação.

\footnotetext{
Lei $n^{\circ}$ 12.527/2011; estabelece o fornecimento de dados e/ou informações da Administração Pública de todos os níveis e Poderes para os cidadãos.

5 Lei $n^{\circ}$ 12.813/2013; estabelece a regulação e organização dos conflitos de interesses dos ocupantes de cargos públicos do Executivo Federal em relação aos interesses privados.

6 Lei $\mathrm{n}^{\circ}$ 12.846/2013; estabelece a responsabilização civil e administrativa de pessoas jurídicas que de alguma
} forma lesionaram a Administração Pública. 
Por outro lado, a CRG coordena os processos disciplinares, desempenhando a função de responsabilização de todas as apurações de irregularidades no nível federal, além de suas devidas punições e ações disciplinares.

Porém, a alteração de maior envergadura aconteceu em 12 de maio de 2016, em meio ao afastamento da presidente Dilma Rousseff e atuação do então presidente em exercício Michel Temer, o qual extinguiu a Controladoria-Geral da União e instituiu, preliminarmente, o Ministério da Transparência, Fiscalização e Controle, por meio da Medida Provisória no 726/2016. Preliminarmente, pois a repercussão da extinção da CGU reverberou negativamente entre setores da sociedade e do próprio órgão que temiam o seu desmantelamento e uma possível tentativa de enfraquecer o combate à corrupção.

Assim, após tramitar no congresso nacional, a MPV n ${ }^{0} 726 / 2016$ foi convertida na lei $\mathrm{n}^{\circ} 13.341 / 2016$, em 29 de setembro daquele ano, reinserindo o antigo nome, passando a se chamar de Ministério da Transparência, Fiscalização e Controladoria-Geral da União, garantindo a manutenção do uso da sigla CGU de forma oficial. O novo órgão abarcou todas as funções da precedida CGU, expressa no Art. $6^{\circ}$, Inc. II, da Lei $n^{\circ} 13.341 / 2016$, para o qual dispõe que "Ficam transferidas as competências: (...) da Controladoria-Geral da União para o Ministério da Transparência, Fiscalização e Controladoria-Geral da União - CGU”.

Tendo em vista o caráter recente dos fatos, ainda não é possível avaliar com profundidade os impactos das mudanças sobre o controle propriamente. $\hat{E}$ fato, porém, que a CGU já possuía classe e força de ministério, porém, alocado na estrutura da Presidência da República. Dessa forma, o principal acontecimento dessa alteração é a mudança de sua localização institucional dentro da administração federal. Do ponto de vista jurídico e normativo foram encontradas modificações que estão analisadas no próximo bloco.

Antes, apresenta-se abaixo o resumo das principais modificações na estrutura do controle interno federal desde 2001, ano de surgimento do primeiro órgão com classe de ministério a centralizar a atividade, até a última alteração de 2016.

\section{DA PRESIDÊNCIA PARA A ESPLANADA}

O Art. $6^{\circ}$, Inc. II, da Lei ${ }^{\circ} 13.341 / 2016$, citado acima, não deixa dúvidas de que o novo órgão absorveu todas as competências daquele que o antecedeu. Contudo, essa reestruturação inédita abriu também espaço para a redefinição de detalhes da atuação. A começar pela própria definição, o qual era disposto que à Controladoria-Geral da União competia 
“(...) assistir direta e imediatamente ao Presidente da República no desempenho de suas atribuições, quanto aos assuntos e providências que (...) sejam atinentes à defesa do patrimônio público, ao controle interno, à auditoria pública, às atividades de ouvidoria-geral e ao incremento da transparência da gestão no âmbito da Administração Pública Federal" (Art. 17 da Lei $\mathrm{n}^{\circ} 10.683 / 2003$, grifo nosso).

Na redação acerca do Ministério da Transparência e Controladoria-Geral da União está disposto que a ele compete as "providências necessárias à defesa do patrimônio público, ao controle interno, à auditoria pública, à correição, à prevenção e ao combate à corrupção, às atividades de ouvidoria e ao incremento da transparência da gestão no âmbito da administração pública federal" (Inc. I, Art. 65 da MPV n ${ }^{\circ} 782 / 2017$, grifo nosso).

Ao se comparar a redação da legislação de 2003 com aquela descrita em 2017, verifica-se que todas as antigas funções permaneceram intactas (defesa do patrimônio público, controle interno, auditoria pública e ouvidoria) e foram acrescidas outros itens fortalecedores da atividade (correição, prevenção e combate à corrupção), já nas definições iniciais. A presidência, entretanto, não se faz mais presente na condução dos trabalhos. Em outras palavras, a nova organização deu autonomia institucional para o órgão conduzir as ações sem depender da orientação da Presidência da República. O foco dado nas atividades de controle, portanto, formalmente passaram de ações de governo para ações de Estado.

Uma outra alteração a ser ponderada é em relação às definições do que compreendem as atividades de controle interno no Poder Executivo Federal. Desde a criação recente da então Corregedoria-Geral da União, em 2001, era disposto que "Cumpre à Corregedoria-Geral da União, (...) instaurar sindicância ou processo administrativo ou, conforme o caso, representar ao Presidente da República para apurar a omissão das autoridades responsáveis" (Artigo 14-A, \$20 da MPV n ${ }^{\circ}$ 2.143-31/2001, grifo nosso). Ou seja, toda e qualquer passividade de dirigentes encontradas pelo órgão deveria, por força de lei, ser comunicada ao presidente da república para as devidas providências. Tal disposição foi mantida mesmo com a sua transformação em Controladoria-Geral da União, em 2003, constando integralmente na Medida Provisória $n^{\circ} 103 / 2003$ e na Lei ${ }^{\circ}$ 10.683/2003, ambos no $\$ 20$ do Artigo 18, sem alteração da obrigatoriedade de representação ao presidente da república.

Porém, na última reforma de 2016, ao extinguir a CGU e criar o Ministério da Transparência, Fiscalização e Controle, a Medida Provisória nº 726/2016 deu nova redação, dispondo que "Cumpre ao Ministério da Transparência, Fiscalização e Controle, (...) instaurar sindicância ou processo administrativo ou, 
conforme o caso, representar a autoridade competente para apurar a omissão das autoridades responsáveis" (Art. 12 da MPV 726/2016, grifo nosso). Esse dispositivo foi mantido pela Lei 13.341/2016 e, inclusive, na mais recente Medida Provisória $n^{0} 782 / 2017$, que estabeleceu a nova estrutura para o Executivo Federal e simplificou a nomenclatura do órgão para Ministério da Transparência e Controladoria-Geral da União.

Ao não explicitar mais o presidente da república nos casos de omissão das demais autoridades, verifica-se que a responsabilidade do chefe do Executivo Federal foi delegada às outras "autoridades competentes". Antes da transformação em ministério, a CGU detinha a competência legal de envolver diretamente o presidente da república, o que o poderia incorrê-lo em prevaricação, ou seja, numa falta de cumprimento do dever de defender o interesse público. Agora, havendo uma autoridade imediata competente ao agente omisso, cessou-se o envolvimento direto do presidente e sua consequente responsabilização.

Vale mencionar que essa alteração no detalhamento das disposições acerca do controle interno não significou uma redução da importância do órgão propriamente, uma vez que se mantiveram as demais competências de controle, tendo as competências finalísticas permanecidas inalteradas pela Lei 13.341/2016. Porém, cabe ressaltar que a não obrigatoriedade de acionar e envolver a Presidência da República é um grau de enfraquecimento de parte do processo de controle, demonstrando uma fragilização, em que o conjunto da manobra foi flexibilizada, abrindo brecha para a condução de sindicâncias ou processos administrativos em níveis inferiores, ante a ciência e providências direta do presidente da república.

Além desse afastamento jurídico do presidente no controle interno, frisa-se a saída institucional do órgão da estrutura de assessoramento da Presidência da República. De 2001 a 2016, a CGU, seja como Corregedoria ou como Controladoria, foi consolidada como uma autêntica agência anticorrupção e salvaguardada pela prerrogativa de enfrentar a malversação da atividade pública pela representação da instituição Presidência da República.

O status de um órgão incumbido de conduzir investigações sobre as ações dos pares é um fator que deve ser considerado em sua organização. Ainda que simbolicamente, pois a CGU já possuía classe de ministério, estar alocado na estrutura do nível mais alto da república permite que seja emanada a autoridade necessária aos trabalhos de combate às irregularidades e corrupções. Do ponto de vista da estrutura formal, aquela formalmente representada, o órgão não sofreu alteração, porém, do ponto de vista da estrutura informal, 
daquela oriunda das relações espontâneas, houve o nivelamento para com os demais ministérios e órgãos sujeitos à sua apreciação direta.

A posição administrativa é uma questão importante para o funcionamento de uma organização. De acordo com Chiavenato (2003), o princípio da distribuição de autoridade se relaciona com a amplitude administrativa, ou amplitude de controle, o qual implica diretamente no peso de decisão. Diminui-se, portanto, o direito de comando conforme se iguala numa estrutura hierárquica. Ou seja, é essencial ao controle da gestão a efetiva delegação de autoridade.

Para tanto, vale mencionar que Pires e Gomide (2014), ao considerar que a capacidade estatal se refere à amplitude do Estado implementar e executar políticas, tal termo é explicado por meio de dois componentes. Uma representada pelo técnico-administrativo, ou seja, pelas habilidades do Estado de efetivar suas políticas, "produzindo ações coordenadas e orientadas para a geração de resultados" (PIRES; GOMIDE, 2014, p. 14). Outro, porém, é o componente político, em que se faz a habilidade de inclusão dos diversos atores numa negociação, de forma a envolver e processar os conflitos, "prevenindo a captura por interesses específicos" (PIRES; GOMIDE, 2014, p. 14). Trata-se dos arranjos que sustentam a implementação das políticas públicas, permitindo assim, a descrição e visualização das capacidades num formato de avaliação.

Assim, na análise de políticas públicas, conforme Pires e Gomide (2014) os componentes técnico-administrativo e político se operacionalizam na análise das avaliações ao demonstrarem as variações em arranjos institucionais das políticas. As combinações dos níveis de prevalência de cada componente demonstram as capacidades e/ou debilidades, por exemplo.

Logo, o arranjo institucional do controle, caracterizado por uma trajetória de solidificação do quadro próprio de efetivos para o desempenho das funções, sobretudo como resposta ao esforço de combate à corrupção, teve a influência direta da opinião pública, favorecendo, em muitos casos, a implementação top-down da política de controle interno, uma vez que parte significativa do desenvolvimento se deu por meio de decretos da presidência e pouca articulação burocrática intergovernamental. Assim, na releitura da perspectiva de Pires e Gomide (2014), a capacidade técnico-administrativa, apesar da solidez na atuação, possui pouca margem discricionária, sendo a capacidade política ressaltada, conforme vivenciado nas transições presidenciais, especialmente do ano 2000 em diante. 


\section{CONCLUSÃO}

O estudo da formação histórica das burocracias de controle interno e de suas recentes modernizações é aspecto relevante na manutenção de uma memória histórica a luz de uma análise da trajetória institucional, facilitando a própria compreensão do controle interno aqui discorrido, sobretudo por ser esta estrutura a ponta de lança da política voltada à integridade governamental.

Importante na formação e estruturação da capacidade estatal de controle e defesa do Estado, a evolução da arquitetura institucional ao longo do desenvolvimento histórico demonstra o fortalecimento do controle interno por meio da centralização administrativa, criação de quadros próprios, e formalização legal das competências de órgão fiscalizador. Iniciada ainda no período colonial, focando nos desvios de matérias primas e de metais, a preocupação à época do agente era defender os cofres da coroa contra o vazamento negligente de recursos. Hoje, três séculos passados, a essência da lógica permanece, porém, reorientada no sentido de buscar também a eficiência da gestão e na gestão, defendendo-se o interesse público.

Destaca-se que as mudanças empreendidas nas instituições públicas, originárias de pressões da interação da sociedade com o estado, são produtoras de importantes modificações governamentais, sobretudo no âmbito da gestão, eficácia e democracia (VARELA ÁLVAREZ, 2003). Considerando que a criação da Corregedoria-Geral da União (2001) surgiu como uma resposta ao enfrentamento da corrupção, sendo assim alocada na estrutura da Presidência da República, a transformação da Controladoria-Geral da União (2003) em Ministério da Transparência (2016) seguiu uma lógica distinta de resposta à sociedade.

A reestruturação da CGU em Ministério da Transparência e Controladoria-Geral da União ocorreu em um momento de contingenciamento, frente a crise econômica, e de um importante momento político, decorrente do segundo impeachment de presidente da história brasileira. Nesse sentido, a manutenção da identidade CGU, mesmo como ministério, após a sua retirada pela MPV $\mathrm{n}^{\circ}$ 726/2016 e retomada pela Lei ${ }^{\circ}$ 13.341/2016, indica a consolidação ao longo da história da política de combate à corrupção pautada pela ideia de uma agência central independente de controle e correição.

As reformas administrativas são uma dinâmica de contextualização das mudanças contemporâneas (VARELA ÁLVAREZ, 2003). As pressões democráticas por mais e melhores serviços, conscientização do cidadão como usuário e financiador, além da incorporação de novos problemas nas agendas governamentais, fazem parte de uma série de mudanças que refletiram diretamente 
na condução dos governos. Para Varela Álvarez (2003), as reformas precisam corresponder coerentemente com a administração pública frente às novas competências e transformações na democratização do Estado.

Deslocar o principal órgão de fiscalização, auditoria e combate à corrupção para a mesma posição institucional das demais unidades e órgãos é, indiretamente, o rebaixamento da autoridade hierárquica. A CGU, enquanto órgão da Presidência da República, beneficiava-se do arcabouço projetado pela própria vinculação a este. Não dispor, inclusive, de nomenclatura associada à ministérios, apesar do status, induzia para um reconhecimento de órgão independente, ou seja, de uma agência técnica e especializada nas incursões de combate à corrupção e irregularidades, tal como se observou ao longo da trajetória formativa. Ao compor a Esplanada dos Ministérios, além de se alocar no mesmo patamar dos fiscalizados, é possível uma vinculação à ideia de loteamento por busca de apoio, tal como ocorre no presidencialismo de coalizão (ABRANCHES, 1988), e de troca do comando da pasta a mercê do rodízio político.

Reitera-se, no entanto, que ainda é precipitado fazer uma projeção dos efeitos desta última mudança. É seguro, porém, afirmar que a capacidade estatal de controle interno e defesa administrativa do Estado brasileiro observou substancial ganho no último século, sobretudo desde a virada do milênio.

A centralização de atividades, antes segregadas de acordo com as finalidades (auditoria na Fazenda e ouvidoria na Justiça, por exemplo), e ademais a estruturação do órgão por meio do remanejamento de pessoal especificamente dedicados à tarefa, favoreceu a criação de uma organização estatal relevante o suficiente para enfrentar os desafios na mesma proporção. Além de fortalecer o termo "CGU" como sinônimo de combate à corrupção, a temática do controle interno vem se consolidando nas agendas governamentais e impulsionando as atividades com novas leis de promoção da integridade no setor público, demonstrando o seu impulso como política pública de defesa do Estado.

Como a melhoria da capacidade de gestão do Estado depende fundamentalmente de sua própria estabilidade, tanto no âmbito econômico, como na parte administrativa (BRESSER-PEREIRA, et al. 1998), o controle interno e o modelo gerencial apresentam características similares ao favorecerem a formação de um aparato burocrático capacitado na regulação da gestão pública nos limites da legalidade e probidade. A eficácia, eficiência e efetividade são princípios em comum na democratização do poder público, não sendo objetivo da reforma na gestão pública a supressão de serviços e/ou instituições (BRESSER-PEREIRA, 2001). 
Nesse sentido, Araújo (2013) identifica que os constantes desafios emergidos da sociedade carecem de novas formas de organização do poder público, sobretudo daquelas gestadas pela Nova Gestão Pública. De maneira a preservar as suas autonomias, estes desafios são integrados racionalmente às estruturas, observando com isso a coordenação estratégica das atividades num modelo crescente identificado como "Nova Governação Pública" (ARAÚJO, 2013, p. 54).

A evolução do controle interno governamental, para além do controle de contas, pode ser originária dessa Nova Governação Pública. Isso porque essa nova corrente tem como foco a correção das "limitações teóricas e práticas dos modelos que a precederam, abrangendo a complexidade atual" (LYNN, 2010, apud ARAÚJO, 2013, p. 55), administrando todas as pluralidades de atores e serviços do Estado atual. É, portanto, um "Estado que é pluralista, onde múltiplos processos informam o sistema para a formulação das políticas públicas" (ARAÚJO, 2013, pp 55), relacionados por sua vez, numa relação de network e de crescente interdependência inter e intra-organizacional para se buscar a melhor performance da política pretendida.

\section{BIBLIOGRAFIA}

ABRANCHES, Sergio. Presidencialismo de coalizão: o dilema institucional brasileiro. Dados: Revista de Ciências Sociais, Rio de Janeiro: IUPERJ, vol. 31, no 1, pp. 3-55, 1988.

ARAÚJO, Joaquim Filipe. Da Nova Gestão Pública à Nova Governação Pública: pressões emergentes da fragmentação das estruturas da Administração Pública. In: H. Silvestre; J. F. Araújo (Coord.). Coletânea em Administração Pública. Lisboa: Escolar Editora, pg. 25-61, 2013.

BRASIL. Controladoria-Geral da União. Relatório de Gestão - Exercício 2015. Brasília. Disponível em: $<$ http://www.cgu.gov.br/sobre/auditorias/arquivos/2015/relatorio-degestao-cgu-2015.pdf>. Acesso em: 07 set. 2017.

BRESSER-PEREIRA, Luiz Carlos; et al. Una nueva gestión pública para América Latina. Documento del CLAD, 1998.

BRITO, Jaime Ricardo. Breve Histórico do Controle Interno do Poder Executivo Federal: Origem, evolução. Modelo atual e visão futuro. Revista de Negócios: Business Review. ISSN 1980-2080. No. 7-Mar./2009.

CHIAVENATO, Idalberto. Introdução à teoria geral da administração: uma visão abrangente da moderna administração das organizações. Rio de Janeiro: Elsevier, 2003.

NAKANO, Bruno Massayuki. A organização do aparato de controle políticoadministrativo do Brasil e da Espanha: Diferenças e similaridades do controle interno. In: Congresso Brasileiro de Políticas Públicas e Gestão Governamental, II, 2017, Belo Horizonte. Anais eletrônicos: Belo Horizonte, pp. 86-99 2017. 
O 'DONNELL, Guillermo. Accountability horizontal e novas poliarquias. Lua Nova, São Paulo, n. 44, p. 27-54, 1998. Disponível em: <http://www.scielo.br/scielo. php?script=sci_arttext\&pid=S0102-64451998000200003\&lng=en\&nrm=iso $>$. Acesso em: 07 set. 2017.

OLIVIERI, Cecília. A lógica política do controle interno - O monitoramento das políticas públicas no presidencialismo brasileiro. São Paulo: Ed Annablume, 2010.

OLIVIERI, Cecília. Os controles políticos sobre a burocracia. Rev. Adm. Pública, Rio de Janeiro, v. 45, n. 5, p. 1395-1424, Oct. 2011. Disponível em: <http://www.scielo.br/scielo. php?script=sci_arttext\&pid=S0034-76122011000500007\&lng=en\&nrm=iso . Acessado em: 07 set. 2017.

OLIVIERI, Cecília; NAKANO, Bruno Massayuki. Controle Interno nos Estados Brasileiros: Evolução, Transparência e Desempenho. In: Congreso Internacional del CLAD sobre la Reforma del Estado y de la Administración Pública, XIX, 2014, Quito. Anais eletrônicos: Quito, 2014. Disponível em: <http://siare.clad.org/fulltext/0077915. pdf $>$. Acesso em: 07 set. 2017.

PIRES, Roberto Rocha; GOMIDE, Alexandre. Burocracia, democracia e políticas públicas: arranjos institucionais de políticas de desenvolvimento. Texto para Discussão 1940, Ipea, 2014.

SALVADOR SERNA, Miquel. El papel de las instituciones en la gestión de las administraciones públicas. Revista CLAD Reforma y Democracia. Caracas, nº 20, 2001.

VARELA ÁLVAREZ, Enrique José. Las Administraciones Públicas Contemporáneas en España - Una visión multidisciplinar desde el estado de las autonomías. Santiago de Compostela: Tórculo Edicións, 2003.

VARELA ÁLVAREZ, Enrique José. Gestión Pública y Gobernanza Local en Perspectiva Comparada - Las políticas de modernización administrativa en los gobiernos locales de Galicia y el norte de Portugal. 2010. 497 f. Tese (Doutorado em Ciência Política). Facultad de Ciencias Políticas y Sociología, Univerdidad Complutense de Madrid, Madri.

\section{LEGISLAÇÕES}

BRASIL, Decreto no 4.177, de 28 de março de 2002. Diário Oficial da União, Poder Executivo, Brasília, DF, 01 abr. 2002.

BRASIL, Decreto ${ }^{\circ}$ 4.308, de 19 de julho de 2002. Diário Oficial da União, Poder Executivo, Brasília, DF, 22 jul. 2002.

BRASIL, Decreto ${ }^{\circ}$ 4.490, de 28 de novembro de 2002. Diário Oficial da União, Poder Executivo, Brasília, DF, 29 nov. 2002.

BRASIL, Decreto ${ }^{\circ}$ 84.362, de 31 de dezembro de 1979. Diário Oficial da União, Poder Executivo, Brasília, DF, 31 dez. 1979. Seção 1, p. 20.136. 
BRASIL, Decreto ${ }^{\circ}{ }^{92.452}$, de 10 de março de 1986. Diário Oficial da União, Poder Executivo, Brasília, DF, 11 mar. 1986.

BRASIL. Decreto-Lei no 200, de 25 de fevereiro de 1967. Diário Oficial da União, Poder Executivo, Brasília, DF, 27 fev. 1967.

BRASIL, Lei ${ }^{\circ} 10.180$, de 06 de fevereiro de 2001. Diário Oficial da União, Poder Legislativo, Brasília, DF, 07 fev. 2001. Seção 1, p. 2.

BRASIL, Lei n ${ }^{\circ} 10.683$, de 28 de maio de 2003. Diário Oficial da União, Poder Legislativo, Brasília, DF, 29 mai. 2003. Seção 1, p. 2.

BRASIL, Lei n ${ }^{\circ}$ 13.341, de 29 de setembro de 2016. Diário Oficial da União, Poder Legislativo, Brasília, DF, 30 set. 2016. Seção 1, p. 10.

BRASIL, Medida Provisória $n^{\circ}$ 103, de or de janeiro de 2003. Diário Oficial da União, Poder Executivo, Brasília, DF, or jan. 2003. Seção 1 - Edição Especial, p. 1.

BRASIL, Medida Provisória nº 2.143-31, de 02 de abril de 2001. Diário Oficial da União, Poder Executivo, Brasília, DF, 03 abr. 2001. Seção 1, p. 1.

BRASIL, Medida Provisória nº 480, de 27 de abril de 1994. Diário Oficial da União, Poder Executivo, Brasília, DF, 28 abr. 1994. Seção 1, p. 6.149.

BRASIL, Medida Provisória n ${ }^{\circ} 726$, de 12 de maio de 2016. Diário Oficial da União, Poder Executivo, Brasília, DF, 12 mai. 2003. Seção I - Edição Extra B, p. 1.

BRASIL, Medida Provisória $n^{\circ} 782$, de 31 de maio de 2017. Diário Oficial da União, Poder Executivo, Brasília, DF, 31 mai. 2017. Seção 1 - Edição Extra e retificado em 02 jun. 2017. 
